\title{
A Simplified Method for the Assessment of Groundwater Vulnerability to Contamination
}

\author{
Rida Al-Adamat*, Abdel Al-Rahman Al-Shabeeb \\ Department of GIS and Remote Sensing, Institute of Earth and Environmental Sciences, Al al-Bayt University, Mafraq, Jordan \\ Email: *ridaali@aabu.edu.jo
}

How to cite this paper: Al-Adamat, R. and Al-Shabeeb, A.A.-R. (2017) A Simplified Method for the Assessment of Groundwater Vulnerability to Contamination. Journal of Water Resource and Protection, 9, 305321.

https://doi.org/10.4236/jwarp.2017.93020

Received: January 29, 2017

Accepted: February 25, 2017

Published: February 28, 2017

Copyright $\odot 2017$ by authors and Scientific Research Publishing Inc. This work is licensed under the Creative Commons Attribution International License (CC BY 4.0).

http://creativecommons.org/licenses/by/4.0/

\begin{abstract}
In this study, an attempt was made to develop a new simplified groundwater vulnerability to contamination index (SGVI). Nine experts in the fields of groundwater, surface water, soil, landuse and GIS were interviewed to develop the new index. They were asked to agree on new parameters that could be used to investigate groundwater vulnerability. Data about such parameters must be affordable and inexpensive. Subsurface parameters were excluded due to the fact that most researchers might not have adequate data about them. The experts agreed that depth to groundwater, soil texture, lineament density, rainfall, topographic slope, drainage density and landuse/land cover parameters should be included in the new vulnerability index. The experts were also asked to give a weight and the ratings for each parameter. The weights given by the experts were subjected to AHP analysis to determine the exact weight for each parameter. An area of $3200 \mathrm{~km}^{2}$ in the northern part of Jordan was selected to test the SGVI. The final map of the SGVI showed that most of the area (more than 96\%) had moderate-low and moderate-high vulnerability to contamination. The new index was also subjected to statistical analysis, map removal test and map removal sensitivity analysis. The outcomes of these analyses showed that the new index was applicable and could be used in areas where subsurface data was limited or not available.
\end{abstract}

\section{Keywords}

SGVI, Groundwater, Vulnerability, Contamination, AHP

\section{Introduction}

The maps of Groundwater vulnerability to contamination are important tools used to assist the landuse planners in addressing the problems that groundwater might have as a result of changing the landuse in a certain area. It is also used to predict the pollutants movement in the soil. This will allow planners to modify the po- 
tential harm to groundwater before serious impacts occur [1].

There are several methods used to assess the groundwater vulnerability including process-based mathematical models, statistical methods and overlay and indexing.

The process-based mathematical models are analytical or numerical solutions of mathematical equations to predict the contaminant transport in both space and time, which distinguish them from the other methods. These methods are constrained by the lack of data and the computational difficulties [2].

The statistical models are usually used in evaluating, determining, and quantifying the association between measures of vulnerability and various types of information that could be related to vulnerability. The use of statistical methods is limited by the requirement for high quality data, cost and time constrains [2].

The overlay and index methods are used for combining maps of parameters considered to be important in contaminant, where each attribute is assigned a numerical score based on its perceived importance [2] [3]. The overlay and index methods rely on simple mathematical representations of expert opinion rather than process representation or empirical data. Their major negative aspect is the fact that assigning numerical values to the descriptive entities and relative weights for the different attributes is subjective.

Examples of the developed overlay and index methods include the following (Table 1):

1. DRASTIC ([4]-[11]).

2. GOD ([12] [13] [14]).

3. EPIK ([15] [16] [17]).

4. SINTACS ([18] [19] [20]).

5. PI ([21]).

6. COP ([11], [17] and [22] [23]).

It appears from Table 1 that these methods require subsurface data including

Table 1. Methods and used parameters for groundwater vulnerability assessment.

\begin{tabular}{|c|c|c|c|c|c|c|}
\hline \multirow{2}{*}{ Parameters } & \multicolumn{6}{|c|}{ Methods } \\
\hline & GOD & DRASTIC & SINTACS & EPIK & PI & $\mathrm{COP}$ \\
\hline Topographic slope & & $\checkmark$ & $\checkmark$ & $\checkmark$ & $\checkmark$ & $\checkmark$ \\
\hline Stream network & & & $\checkmark$ & & $\checkmark$ & $\checkmark$ \\
\hline Soil & & $\checkmark$ & $\checkmark$ & $\checkmark$ & $\checkmark$ & $\checkmark$ \\
\hline Net recharge & & $\checkmark$ & $\checkmark$ & $\checkmark$ & $\checkmark$ & $\checkmark$ \\
\hline Unsaturated zone & $\checkmark$ & $\checkmark$ & $\checkmark$ & $\checkmark$ & $\checkmark$ & $\checkmark$ \\
\hline Depth to water & $\checkmark$ & $\checkmark$ & $\checkmark$ & & $\checkmark$ & \\
\hline Hydrogeological features & $\checkmark$ & $\checkmark$ & $\checkmark$ & $\checkmark$ & $\checkmark$ & \\
\hline Aquifer hydraulic conductivity & & $\checkmark$ & $\checkmark$ & & & \\
\hline Aquifer thickness & & & $\checkmark$ & & & \\
\hline Land use & & & $\checkmark$ & $\checkmark$ & $\checkmark$ & $\checkmark$ \\
\hline
\end{tabular}


the unsaturated zone (GOD, DRASTIC, SINTACS, EPIK, PI and COP), hydraulic conductivity (DRASTIC and SINTACS) and aquifer thickness (SINTACS). Also, these methods require data about net recharge (DRASTIC, SINTACS, EPIK, PI and COP). These data requirement might restrict researchers and lead them either to estimate or exclude one or more of these parameters. [9] excluded the hydraulic conductivity and estimated the net recharge based on an equation derived by [8].

This research is an attempt to derive a Simplified Groundwater Vulnerability Index (SGVI) based on experts' opinions using available and inexpensive data to assist researchers in assessing groundwater vulnerability as a part of their Environmental Impact Assessment (EIA).

\section{Methodology}

\subsection{Index Development}

The adopted methodology for developing a simplified groundwater vulnerability index (SGVI) was based on the Analytical Hierarchy Process (AHP). AHP is based upon the construction of a series of Pair-Wise Comparison Matrices (PCMs), which compare each criterion to one another. The scale of PWC is divided from 1 to 9 for PCM elements to estimates the relationship between the criteria on the scale $(9,7,5,3,1)$ where the value of 1 suggests that the criteria are equally important and a value of 9 leads one to infer that the criterion under consideration is extremely important in relation to the other criterion with which the comparison is made [24] (Table 2).

The processes of pairwise comparison matrix that are computed to achieve and check the pairwise comparison matrix is acceptable or not are illustrated in Figure 1 ([25] [26] [27]).

Based on [25] [26] [27], the following Equations were used to calculate $\lambda_{\max }$, $C I$, and $C R$

$$
\lambda_{\max }=1 / n \sum_{i=1}^{n}(A . W / W) .
$$

$\lambda$ represents the sum of consistency vectors divided by number of the consistency vector.

Where $A$ is the known judgment matrix and $n$ is the order of the matrix $B$.

Table 2. Scale of relative importance [24].

\begin{tabular}{cccc}
\hline $\begin{array}{c}\text { Intensity of } \\
\text { importance }\end{array}$ & Definition & $\begin{array}{c}\text { Intensity of } \\
\text { importance }\end{array}$ & Definition \\
\hline 1 & $\begin{array}{c}\text { Equal importance } \\
\text { Equal to moderate } \\
\text { importance }\end{array}$ & 6 & $\begin{array}{c}\text { Strong to very strong } \\
\text { importance }\end{array}$ \\
2 & Moderate importance & 7 & Very strong importance \\
3 & $\begin{array}{c}\text { Moderate to strong } \\
\text { importance } \\
\text { Strong importance }\end{array}$ & 9 & Very to extremely strong \\
5 & Extreme importance
\end{tabular}




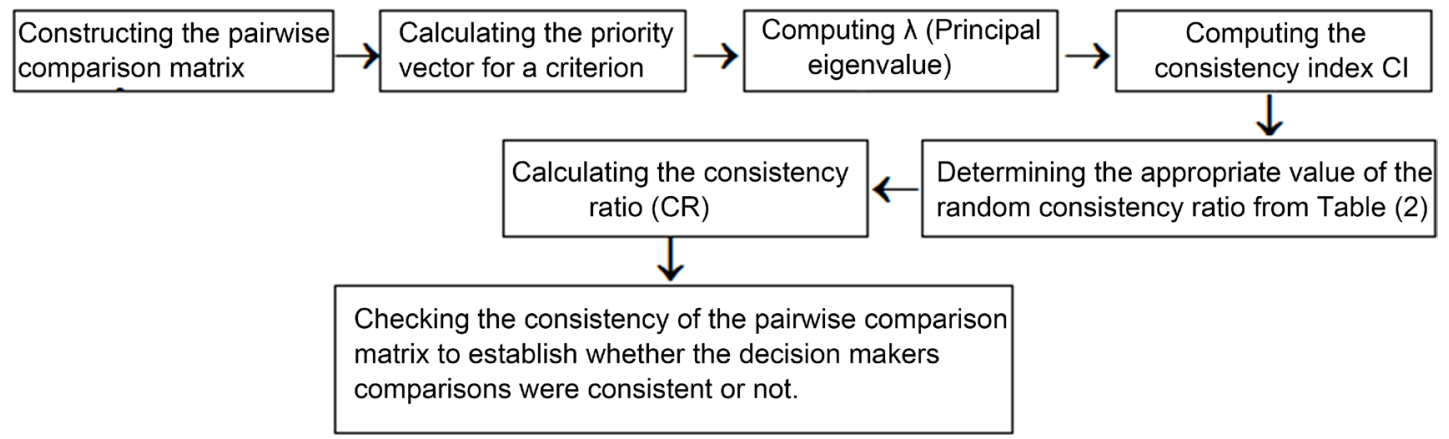

Figure 1. The processes of pairwise comparison matrix.

$$
C I=(\lambda-N) / n-1 \text {. }
$$

$C I$ represents the consistency index based on the observations of $\lambda$.

Where $\lambda_{\max }$ is the average value of the consistency vector, and $n$ is the number of criteria.

The consistency Ratio ( $R I)$ is calculated using Equation (3):

$$
C R=C I / R I \text {. }
$$

Table 3 lists the consistency index of a randomly generated pairwise comparison matrix [27] [28].

In this research, nine experts from various Jordanian universities and organisations in the fields of groundwater, surface water, soil, landuse and GIS were interviewed to suggest a Simplified Groundwater Vulnerability Index (SGVI) that requires inexpensive data. The experts agreed that the following parameters should be included in the groundwater vulnerability index:

- Depth of Groundwater (DG): Depth determines the depth which a contaminant must travel before reaching the aquifer.

- Soil Texture (ST): Soil has a significant impact on the amount of recharge water which infiltrates into the groundwater.

- Lineament Density (LD): Higher values of lineament density might pose more threat to groundwater by allowing contamination to reach the water table.

- Rainfall (RF): Rainfall is the major carrier of contamination to groundwater through infiltration.

- Topographic Slope (TS): Slope controls the likelihood that a pollutant will run off or remain on the surface long enough to infiltrate.

- Drainage Density (DD): Drainage density is a useful measure for runoff potential. High drainage density means higher potential for runoff and hence less infiltration.

- Land Use/Land Cover (LL): Landuse/Land cover affect the potential for groundwater recharge and hence impact the groundwater vulnerability to contamination.

The experts were also asked to put a weight to each parameter based on the supplied simple questionnaire listed in Table 4. The pair-wise comparison matrix of the experts opinions was then calculated (Table 5). Table 6 lists the computed values of weights, $\lambda_{\max }, \mathrm{CI}, \mathrm{RI}$ and CR for experts opinions. Experts were 
Table 3. Average random consistency indices (RI) for different number of criteria.

\begin{tabular}{cccccccccc}
\hline$N$ & $R I$ & $N$ & $R I$ & $N$ & $R I$ & $N$ & $R I$ & $N$ & $R I$ \\
\hline 1 & 0.0 & 4 & 0.90 & 7 & 1.32 & 10 & 1.49 & 13 & 1.56 \\
2 & 0.0 & 5 & 1.12 & 8 & 1.41 & 11 & 1.51 & 14 & 1.57 \\
3 & 0.58 & 6 & 1.24 & 9 & 1.45 & 12 & 1.54 & 15 & 1.59 \\
\hline
\end{tabular}

Table 4. A sample of the questionnaire used to determine the relative importance of index parameters.

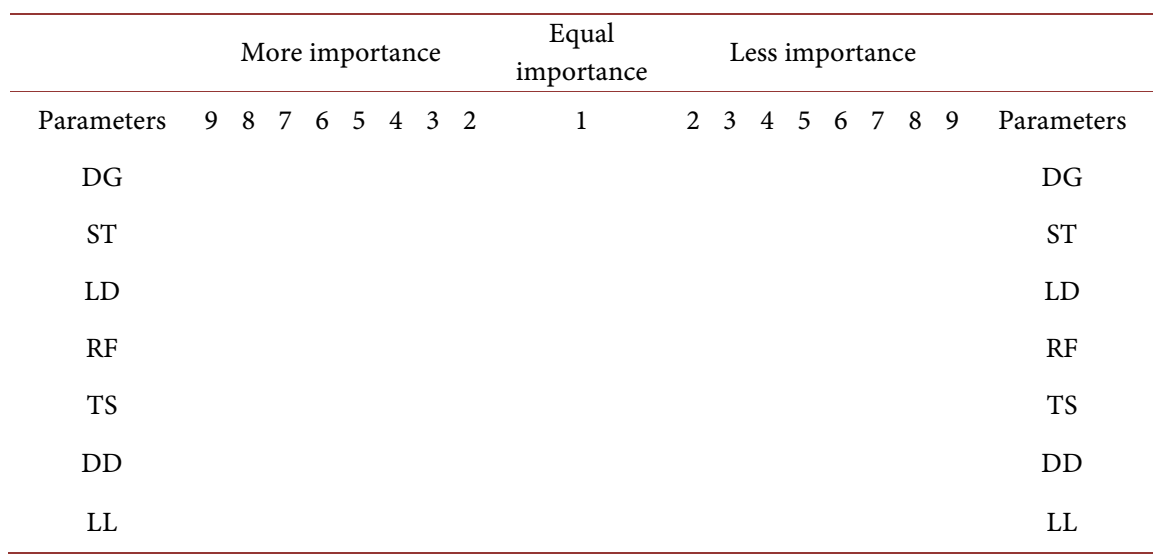

also asked to suggest the ratings for each parameter based a scale 1 (Lowest) to 4 (Highest). Table 7 summarises the ratings and weights for the Simplified Groundwater Vulnerability Index parameters. The final classification of the SGVI is listed in Table 8. Figure 2 illustrates the methodology adopted to calculate the final weights for the SGVI parameters based on the experts' opinions.

\subsection{Investigated Area}

In order to test the SGVI, an area in the Northern part of Jordan was selected as shown in Figure 3.

The investigated has an area of $3200 \mathrm{~km}^{2}$ which comprises $3.59 \%$ of the total area of Jordan. The climate within the investigated area is characterised by hot dry summers and wet cold winters. Rainfall varies between $50 \mathrm{~mm}$ in the South East to $150 \mathrm{~mm}$ in the North West (Figure 4).

Elevation in the area varies between $530 \mathrm{~m}$ above sea level in the South and South East to $1224 \mathrm{~m}$ above sea level in the North near the Syrian border (Figure $5)$.

Surface water flows from the North towards the South and South West. Most of the Drainages is coming from Syria and flow towards the Azraq Oasis to the South of the investigated area (Figure 6).

The soil texture within the investigated area is classified into 4 classes: Loam, Sandy Loam, Silt Loam and Silty Clay Loam as shown in Figure 7. The shallow groundwater aquifer lies at a depth that varies between $160 \mathrm{~m}$ in the South to more than $300 \mathrm{~m}$ in the North. This variation is due to the high variation in ground topography that characterise the area. 
Table 5. The pair-wise comparison matrix of the experts opinions.

\begin{tabular}{cccccccc}
\hline Criteria & DG & ST & LD & RF & TS & DD & LL \\
\hline DG & 1 & 2 & 2 & 2 & 2 & 2 & 2 \\
ST & 0.5 & 1 & 1 & 2 & 2 & 2 & 2 \\
LD & 0.5 & 1 & 1 & 1 & 2 & 2 & 2 \\
RF & 0.5 & 0.5 & 1 & 1 & 1 & 2 & 2 \\
TS & 0.5 & 0.5 & 0.5 & 1 & 1 & 1 & 1 \\
DD & 0.5 & 0.5 & 0.5 & 0.5 & 1 & 1 & 1 \\
LL & 0.5 & 0.5 & 0.5 & 0.5 & 1 & 1 & 1 \\
Sum & 4 & 6 & 6.5 & 8 & 10 & 11 & 11 \\
\hline
\end{tabular}

Table 6. The computed values of weights (priority vector), $C I, R I$ and $C R$ for experts opinions.

\begin{tabular}{cccccccc}
\hline Parameters & DG & ST & LD & RF & TS & DD & LL \\
\hline Weights (priority vector) & 0.244 & 0.18 & 0.162 & 0.136 & 0.099 & 0.09 & 0.09 \\
$\lambda_{\max }$ & & & & 8.071 & & & \\
$C I$ & & & 0.179 & & & \\
$R I$ & & & 1.32 & & \\
$C R$ & & & & & \\
\hline
\end{tabular}

Table 7. Ratings and weights for the SGVI.

\begin{tabular}{cccccc}
\hline \multirow{2}{*}{ Parameters } & Weight & \multicolumn{5}{c}{ Ratings } \\
\cline { 3 - 6 } & & 1 & 2 & 3 & 4 \\
\hline $\mathrm{DD}(\mathrm{m})$ & 0.244 & $>150$ & $100-150$ & $50-100$ & $0-50$ \\
$\mathrm{ST}$ & 0.18 & Loam & Silt Clay Loam & Silt Loam & Sandy Loam \\
$\mathrm{LD}\left(\mathrm{km} / \mathrm{km}^{2}\right)$ & 0.162 & $0-1.5$ & $1.5-2.5$ & $2.5-3.5$ & $>3.5$ \\
$\mathrm{RF}(\mathrm{mm})$ & 0.136 & $<50$ & $50-100$ & $100-300$ & $>300$ \\
$\mathrm{TS}(\%)$ & 0.099 & $>8$ & $4-8$ & $2-4$ & $0-2$ \\
$\mathrm{DD}\left(\mathrm{km} / \mathrm{km}{ }^{2}\right)$ & 0.09 & $>2.25$ & $1.5-2.25$ & $0.75-1.5$ & $0-0.75$ \\
$\mathrm{LL}(\mathrm{Class})$ & 0.09 & $\begin{array}{c}\text { Bare Rock } \\
\text { and Urban }\end{array}$ & Bare Soil & Marab & $\begin{array}{c}\text { Agricultural } \\
\text { and natural } \\
\text { vegetation }\end{array}$ \\
\hline
\end{tabular}

Table 8. Simplified Groundwater Vulnerability Index Classification.

\begin{tabular}{ccccccc}
\hline Class & No Risk & Low & Moderate-Low & Moderate-High & High & Very High \\
\hline Range & $1-1.5$ & $1.5-2$ & $2-2.5$ & $2.5-3$ & $3-3.5$ & $3.5-4$ \\
\hline
\end{tabular}

Figure 2. The adopted methodology for weight calculation. 


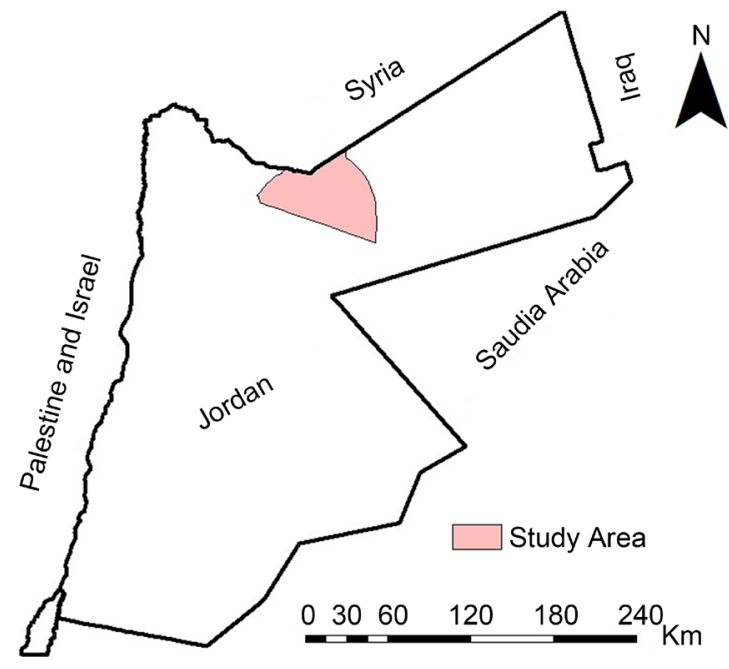

Figure 3. The investigated area within Jordan.

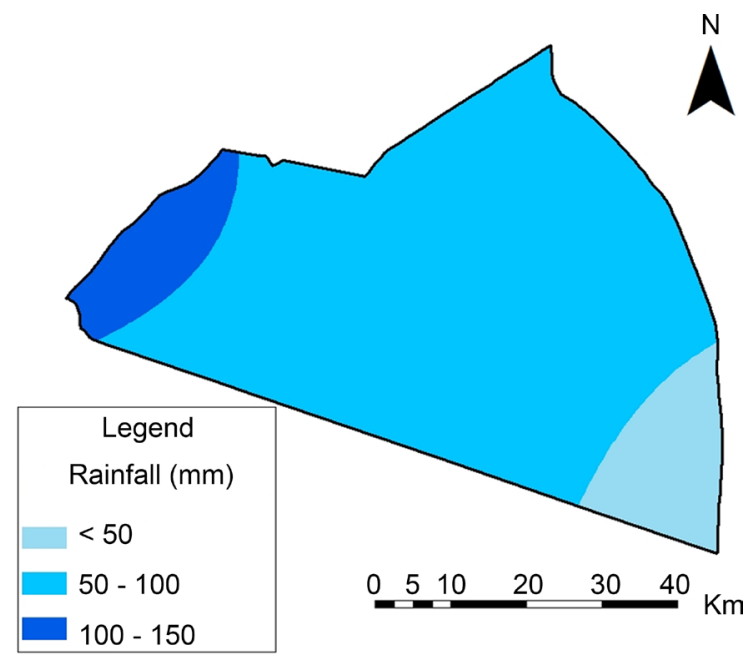

Figure 4. Rainfall isohyets.

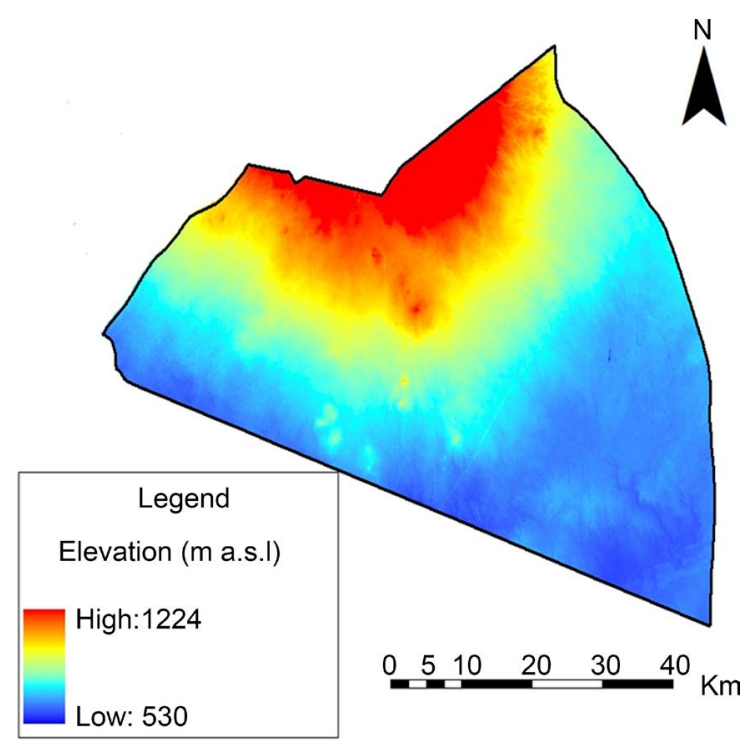

Figure 5. Elevations. 


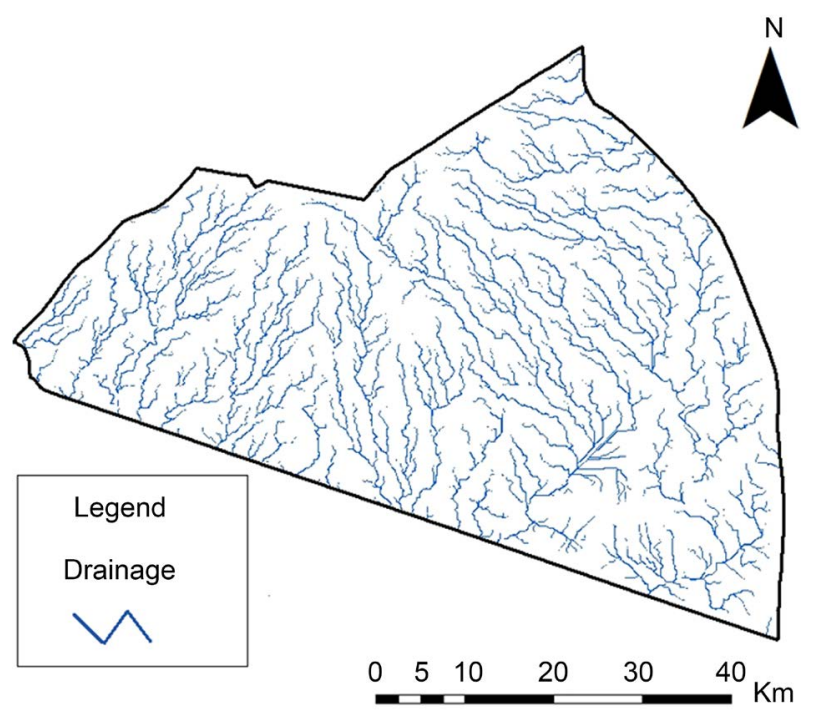

Figure 6. Drainage network.

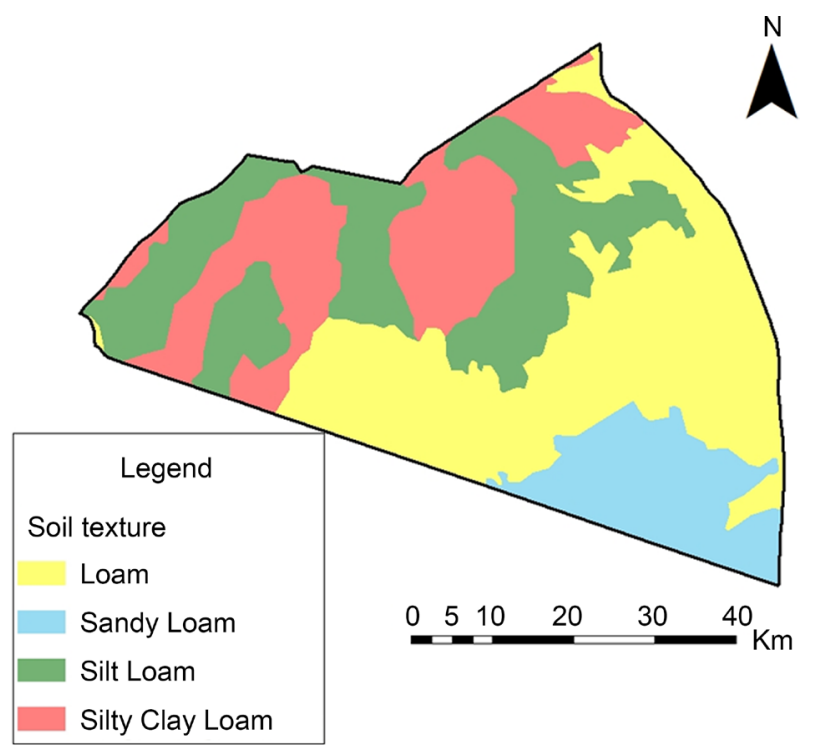

Figure 7. Soil texture.

\subsection{Data Collection}

The data needed for this research were collected at no cost from various resources within Jordan and from internet resources. Table 9 lists the data used in this research and their sources.

\section{Data Analysis and Results}

The following flowchart (Figure 8) shows the methodology adopted within GIS environment to calculate the SGVI. This Figure illustrates the GIS data and tools used to map the final SGVI.

The soil texture map shown in Figure 7 was subjected to GIS manipulation by adding the appropriate ratings according to Table 7. The soil map was then converted into raster format and multiplied by the parameter weight (Figure 9). The 
ST values varied between 0.18 to 0.72 .

The density function in ArcGIS was used to calculate the lineament density for the investigated area, which then classified according to Table 7. The outcome of this operation was then multiplied by the parameter weight (Figure 10). LD varied between 0.162 to 0.648 .

The rainfall isohyets map shown in Figure 4 was subjected to GIS manipulation by adding the appropriate ratings according to Table 7 . The rainfall isohyets map was then converted into raster format and multiplied by the parameter weight (Figure 11). RF values varied between 0.136 to 0.408 .

The slope map for the investigated area was extracted from the ASTER DEM $(30 \mathrm{~m})$ for the investigated area (Figure 5). The slope was classified according to Table 7 and multiplied by the parameter weight (Figure 12). TS values varied between 0.099 to 0.396 .

ASTER DEM was used to generate the drainage map for the investigated area (Figure 6) using the Flow Direction and Flow Accumulation tools in ArcGIS. The density function in ArcGIS was then used to calculate the drainage density for the

Table 9. Used data and their sources.

\begin{tabular}{|c|c|}
\hline Data Type & Source \\
\hline $\begin{array}{l}\text { Depth to } \\
\text { Groundwater }\end{array}$ & Water Authority of Jordan (Excel format) \\
\hline Soil Texture & Jordan Ministry of Agriculture $(1: 250,000)$ \\
\hline Lineament & Natural Resources Authority based on Landat ETM (30 m) \\
\hline Rainfall & Department of Meteorology (Excel format) \\
\hline $\begin{array}{l}\text { Topographic } \\
\text { Slope }\end{array}$ & $\begin{array}{l}\text { ASTER (Advanced Spaceborne Thermal Emission and Reflection Radiome- } \\
\text { ter) DEM }(30 \mathrm{~m})\end{array}$ \\
\hline Drainage & $\begin{array}{l}\text { Extracted from the ASTER DEM using Flow Direction and Flow Accumu- } \\
\text { lation tools }\end{array}$ \\
\hline $\begin{array}{l}\text { Landuse/Land } \\
\text { Cover }\end{array}$ & Extracted from Landsat 8 imagery $(30 \mathrm{~m})$ of August, 2016 \\
\hline
\end{tabular}

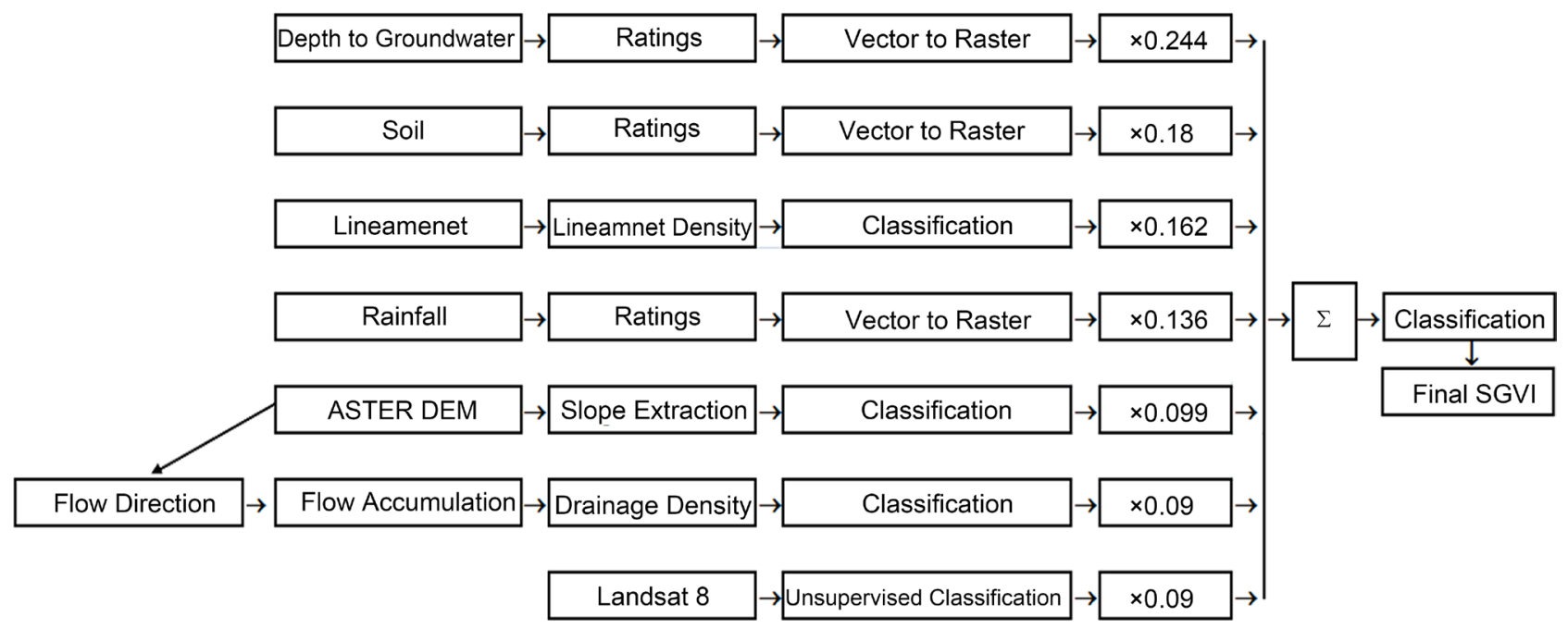

Figure 8. Analysis methodology to calculate the final SGVI. 


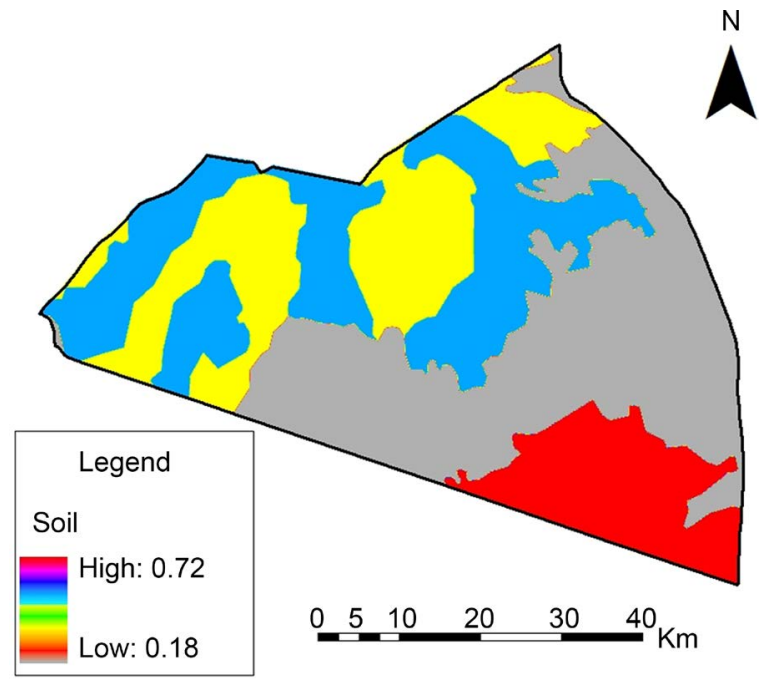

Figure 9. Soil texture parameter.

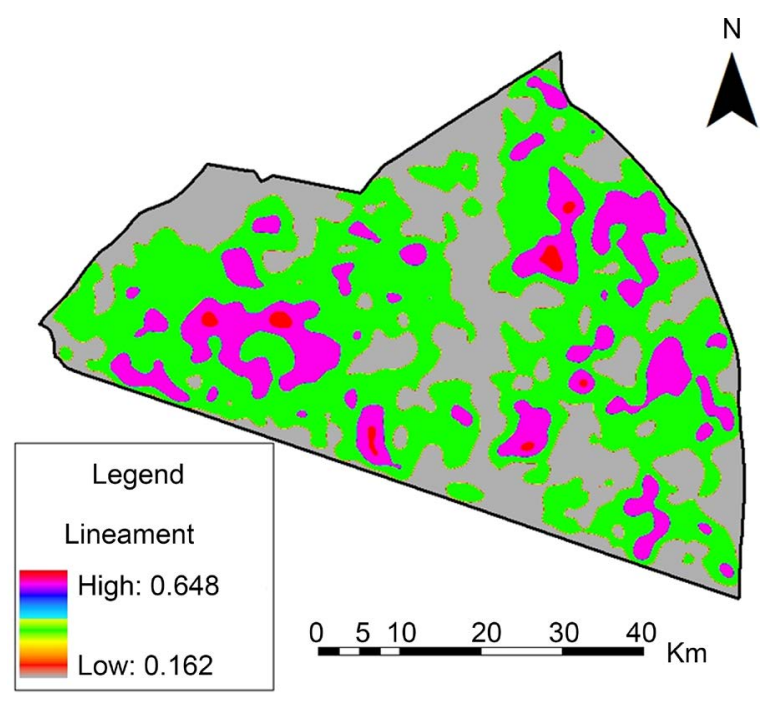

Figure 10. Lineament density parameter.

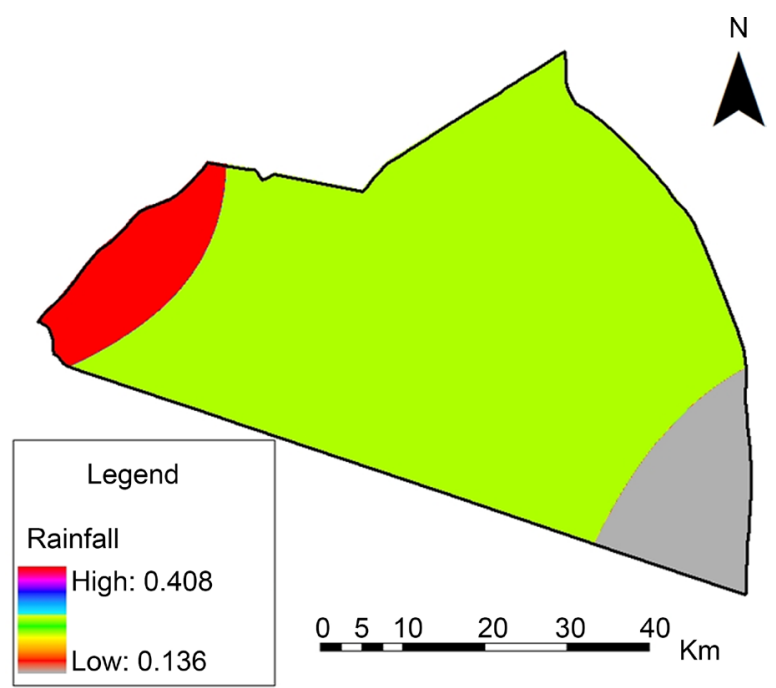

Figure 11. Rainfall parameter. 


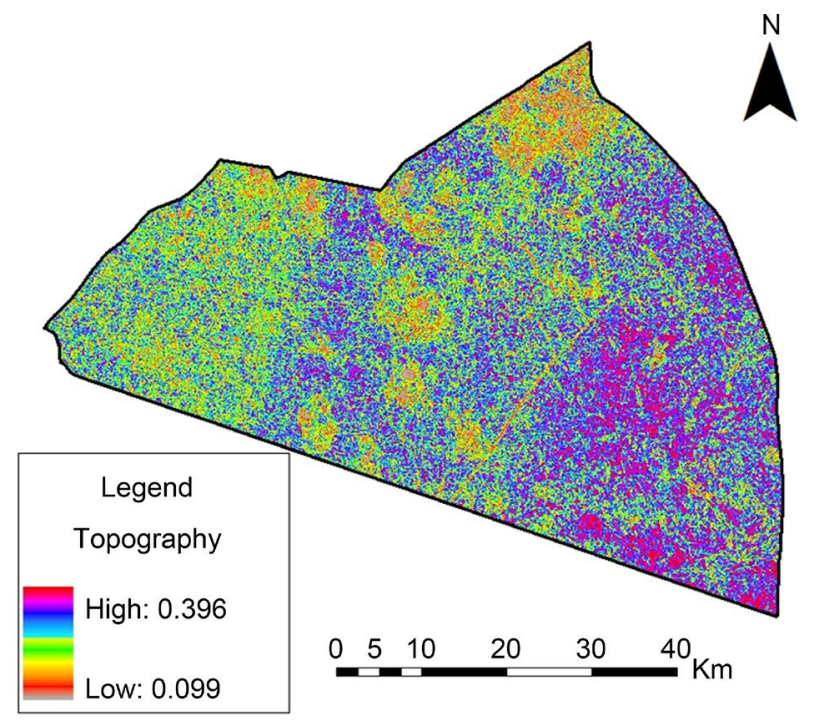

Figure 12. Topographic slope parameter.

investigated area, which then classified according to Table 7. The outcome of this operation was then multiplied by the parameter weight (Figure 13). DS values varied between 0.09 in to 0.36 .

Landsat 8 imagery $(30 \mathrm{~m})$ of August 2016 was used to generate the landuse/land cover map for the investigated area using unsupervised classification technique. The resulted map was subjected to GIS manipulation by adding the appropriate ratings according to Table 7. The landuse/land cover map was then converted into raster format and multiplied by its weight (Figure 14). It appears that LL values varied between 0.09 in most of the investigated area to 0.36 in sporadic patches in the North and North West of the investigated area. Most of the investigated area where given 0.09 due the fact that the dominant land cover in the area is basaltic rocks.

The final SGVI map (Figure 15) is the result of adding all parameters in GIS and then classifying the output based on Table 8. The summary of the SGVI for the investigated area (Table 10) showed that the area with moderate-low vulnerability has an area of $1929.7 \mathrm{~km}^{2}$ (60.3\% of the total area), while the low vulnerability area has an area of $1161.42 \mathrm{~km}^{2}$ (36.3\% of total area). The remaining parts of the investigated area are $102.3 \mathrm{~km}^{2}$ ( $3.2 \%$ of total area) as a moderate-high vulnerability and $6.58 \mathrm{~km}^{2}$ ( $0.2 \%$ of total area) has no risk.

\section{Sensitivity Analysis of the SGVI}

\subsection{Statistical Analysis of the SGVI Parameters}

The statistical analysis for the SGVI parameters (Table 11) indicated that ST and LL parameters contribute the highest risk of contamination with high mean values of 0.384 and 0.358 respectively. The parameters DG, LD, RF, TS and DD contribute moderate risk of contamination with mean values of $0.244,0.298,0.269$, 0.277 and 0.277 respectively.

The ST parameter is highly variable as its coefficient of variation (CV) value is 


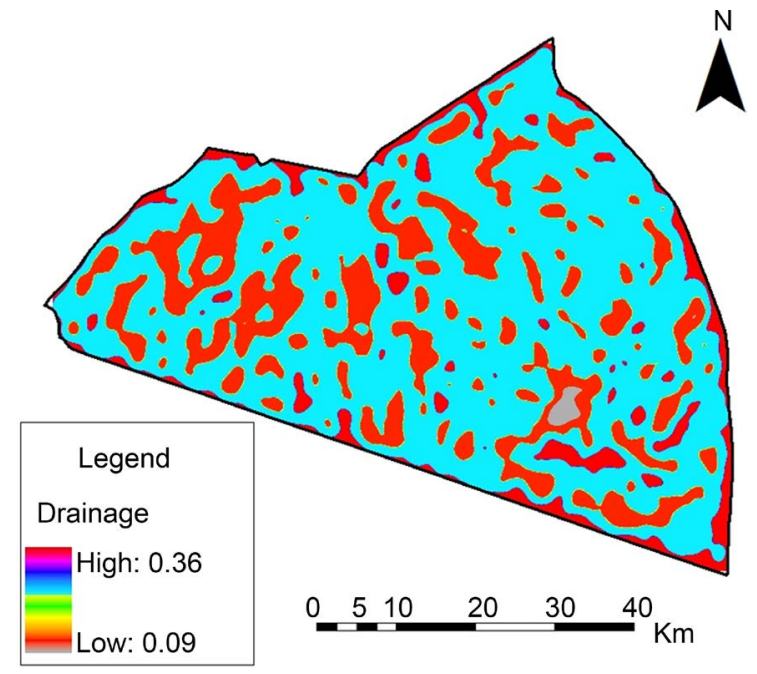

Figure 13. Drainage density Parameter.

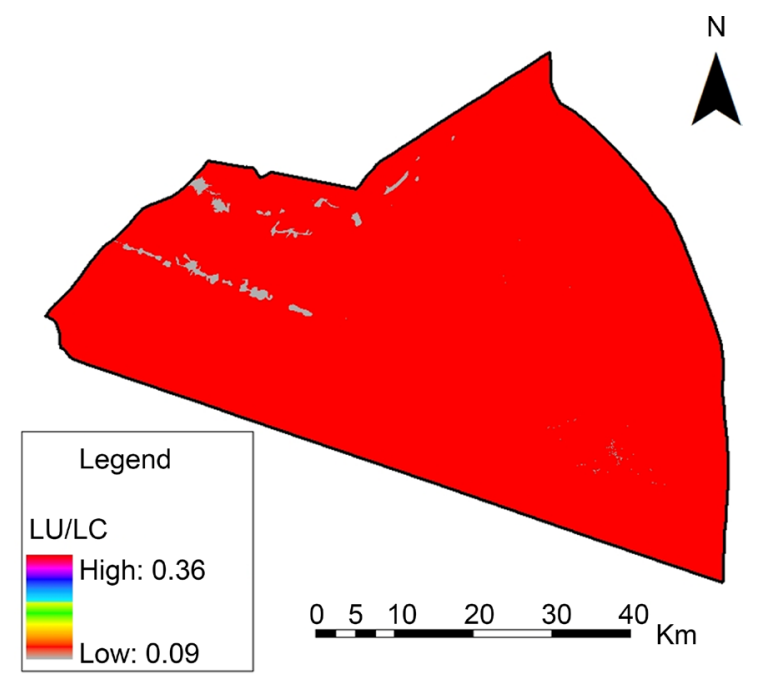

Figure 14. Landuse/land cover Parameter.

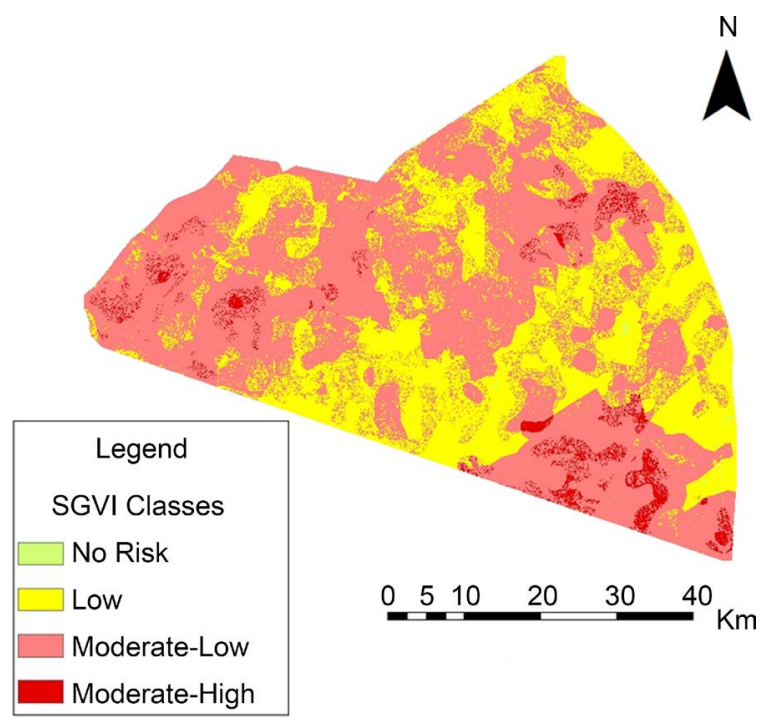

Figure 15. Simplified Groundwater Vulnerability Index (SGVI). 
Table 10. A summary of the SGVI outcome for the investigated area.

\begin{tabular}{ccc}
\hline Class & Area $\left(\mathrm{km}^{2}\right)$ & $\%$ of total area \\
\hline No Risk & 6.58 & 0.2 \\
Low & 1161.42 & 36.3 \\
Moderate-Low & 1929.70 & 60.3 \\
Moderate-High & 102.30 & 3.2 \\
Total & 3200 & 100 \\
\hline
\end{tabular}

Table 11. The statistical summary of the SGVI parameters.

\begin{tabular}{cccccccc}
\hline & DG & ST & LD & RF & TS & DD & LL \\
\hline Min & 0.244 & 0.18 & 0.162 & 0.136 & 0.098 & 0.09 & 0.09 \\
Max & 0.244 & 0.72 & 0.648 & 0.408 & 0.392 & 0.36 & 0.36 \\
Mean & 0.244 & 0.384 & 0.298 & 0.269 & 0.277 & 0.255 & 0.358 \\
SD & 0 & 0.192 & 0.113 & 0.057 & 0.091 & 0.05 & 0.025 \\
CV(\%) & 0.00 & 50.00 & 37.92 & 21.19 & 32.85 & 19.61 & 6.98 \\
\hline
\end{tabular}

$50 \%$. The DG parameter has no variation within the investigated area as it has only a single value for the entire area (0.244). LD, TS, RF and DD are moderately variable with CV values $37.92 \%$ and $32 \%, 21.19 \%$ and $19.61 \%$ respectively. The LL cover parameter is the least variable parameter $(\mathrm{CV}=6.98 \%)$. The sensitivity is calculated based on the rating and weights designated to the feature classes of each parameter.

\subsection{Map Removal Analysis}

The statistics on the removal of one statistically significant parameter on the SGVI values (Table 12) showed that the most important parameters to contamination were DG, DD, RF and TS followed by LD, LL, and ST. The highest values were associated with DG (1.84), DD (1.829), RF (1.815) and TS (1.807). The parameter (ST) showed the lowest sensitivity value (1.701).

\subsection{Map Removal Sensitivity Analysis}

Map removal sensitivity analysis is a test developed by [29]. This test was used in this research to identify the sensitivity of each parameter in the SGVI map. [29] developed an equation (Equation (4)) to calculate the sensitivity index $(S)$ for the parameters used in the vulnerability index.

$$
S=\left|(V / N)-V_{x i} / n\right| .
$$

With: $S$ is the sensitivity index of the parameter.

$V$ is the intrinsic vulnerability index of the method; $N$ is the total number of parameters used to calculate $V ; V_{x i}$ represents the intrinsic vulnerability index obtained after removal of the parameter $X$.

Based on the determined partial indexes (Table 12) and Equation (4), the sen- 
sitivity index was calculated for each parameter of the SGVI (Table 13). Table 13 indicates that all parameters except the DG parameter have a strong influence on the SGVI map. DG with respective sensitivity index of 0.009 has the lowest impact on the SGVI. This is due to the fact that the entire investigated area was given a fixed number of 0.244 to represent this parameter (Depth to groundwater $>150$ $\mathrm{m})$.

\section{Conclusions and Recommendations}

Based on experts' opinions, a new simplified groundwater vulnerability index was developed to investigate groundwater vulnerability to contamination. Seven parameters including depth to groundwater, soil texture, lineament density, rainfall, topographic slope, drainage density, and landuse/land cover were suggested by the experts. The common factor between these parameters is inexpensive data sources to build each one of them. This is in contradiction to the parameters found in other groundwater vulnerability indexes such as GOD, DRASTIC, SINTACS, EPIK, PI and COP.

Based on the outcomes of this research and the statistical tests conducted on the SGVI parameters, it is established that:

- Soil texture and landuse/land cover contribute the highest risk of contamina-

Table 12. The partial index calculated by removing one parameter of the SGVI.

\begin{tabular}{ccccc}
\hline Parameter Removed & Mean & Min & Max & SD \\
\hline DG & 1.84 & 0.983 & 2.666 & 0.226 \\
ST & 1.701 & 1.047 & 2.28 & 0.156 \\
LD & 1.786 & 1.065 & 2.352 & 0.217 \\
RF & 1.815 & 0.966 & 2.638 & 0.227 \\
TS & 1.807 & 1.128 & 2.514 & 0.208 \\
DD & 1.829 & 1.047 & 2.64 & 0.225 \\
LL & 1.726 & 1.001 & 2.55 & 0.225 \\
\hline
\end{tabular}

Table 13. Sensitivity index according to the map removal sensitivity analysis test for SGVI vulnerability map.

\begin{tabular}{ccccc}
\hline \multirow{2}{*}{ Parameters } & \multicolumn{3}{c}{ Sensitivity Index } \\
\cline { 2 - 5 } & $S$ Minimum & $S$ Average & $S$ Maximum & Standard Deviation (SD) \\
\hline DG & 0.000 & 0.009 & 0.029 & 0.005 \\
ST & 0.134 & 0.234 & 0.313 & 0.023 \\
LD & 0.148 & 0.248 & 0.332 & 0.032 \\
RF & 0.130 & 0.253 & 0.370 & 0.033 \\
TS & 0.152 & 0.252 & 0.357 & 0.030 \\
DD & 0.145 & 0.255 & 0.371 & 0.032 \\
LL & 0.134 & 0.238 & 0.356 & 0.032 \\
\hline
\end{tabular}


tion to groundwater while depth to groundwater, lineament density, rainfall, topographic slope and drainage density contribute moderate risk of contamination.

- Depth to groundwater, drainage density, rainfall and topographic slope have the highest importance in the index.

- All parameters have strong impacts on the index except the depth to groundwater.

Based on that, it is concluded that the new simplified groundwater vulnerability index (SGVI) is applicable to investigate groundwater vulnerability to contamination in areas where subsurface data is limited or not available.

Based on this conclusion, it is recommended to test the SGVI in combination with other indexes such DRASTIC, SINTACS or EPIK especially in areas where data for these indexes are available to compare its outcomes with their outcomes. It is also recommended to look for other parameters that might contribute to groundwater vulnerability to contamination under the condition which these parameters are affordable and inexpensive.

\section{Acknowledgements}

The authors of this research would like to acknowledge and appreciate the contribution of the Jordanian experts who assisted the research team in the development of the SGVI index.

\section{References}

[1] Murray, K.S. and Rogers, D.T. (1999) Groundwater Vulnerability, Brownfield Redevelopment and Land Use Planning. Journal of Environmental Planning and Management, 42, 801-810. https://doi.org/10.1080/09640569910830

[2] Evans, T.A. and Maidment, D.R. (1995) A Spatial and Statistical Assessment of the Vulnerability of Texas Groundwater to Nitrate Contamination. Center for Research in Water Resources, Bureau of Engineering Research, Doctoral dissertation, University of Texas, Austin.

[3] NRC (National Research Council) (1993) Ground Water Vulnerability Assessment: Contamination Potential under Conditions of Uncertainty. National Academy Press, Washington DC.

[4] Aller, L., Lehr, J.H., Petty, R. and Bennett, T. (1987) DRASTIC-A Standardized System to Evaluate Groundwater Pollution Potential Using Hydrogeologic Setting. Journal of the Geological Society of India, 29, 23-37.

[5] Evans, B.M. and Myers, W.L. (1990) A GIS-Based Approach to Evaluating Regional Groundwater Pollution Potential with DRASTIC. Journal of Soil and Water Conservation, 45, 242-245.

[6] Stark, S.L., Nuckols, J.R. and Rada, J. (1999) Using GIS to Investigate Septic System Sites and Nitrate Pollution Potential. Journal of Environmental Health, 61, 15-20.

[7] Fritch, T.G., et al. (2000) An Aquifer Vulnerability Assessment of the Paluxy Aquifer, Central Texas, USA, Using GIS and a Modified DRASTIC Approach. Environmental Management, 25, 337-345. https://doi.org/10.1007/s002679910026

[8] Piscopo, G. (2001) Groundwater Vulnerability Map, Explanatory Notes. Castlereagh Catchment, NSW Department of Land and Water Conservation, Wagga. 
http://www.water.nsw.gov.au/_data/assets/pdf_file/0008/549377/quality_groundw ater_castlereagh_map_notes.pdf

[9] Al-Adamat, R.A., Foster, I.D. and Baban, S.M. (2003) Groundwater Vulnerability and Risk Mapping for the Basaltic Aquifer of the Azraq Basin of Jordan Using GIS, Remote Sensing and DRASTIC. Applied Geography, 23, 303-324. https://doi.org/10.1016/j.apgeog.2003.08.007

[10] Abdullah, T., Ali, S. and Al-Ansari, N. (2016) Assessing the Vulnerability of Groundwater to Pollution Using DRASTIC and VLDA Modelsin Halabja Saidsadiq Basin, NE, Iraq. Journal of Civil Engineering and Architecture, 10, 1144-1159.

[11] Abdullah, T., Ali, S., Al-Ansari, N. and Knutsson, S. (2016) Groundwater Vulnerability Using DRASTIC and COP Models: Case Study of Halabja Saidsadiq Basin, Iraq. Engineering, 8, 741-760. https://doi.org/10.4236/eng.2016.811067

[12] Foster, S. (1987) Fundamental Concepts in Aquifer Vulnerability, Pollution Risk and Protection Strategy: International Conference, 1987, Noordwijk Aan Zee, the Netherlands Vulnerability of Soil and Groundwater to Pollutants. Netherlands Organization for Applied Scientific Research, The Hague, 69-86.

[13] Neukum, C. and Hötzl, H. (2007) Standardization of Vulnerability Maps. Environmental Geology, 51, 689-694.

[14] Alvarado, A., Esteller, M.V., Quentin, E. and Expósito, J.L. (2016) Multi-Criteria Decision Analysis and GIS Approach for Prioritization of Drinking Water Utilities Protection Based on Their Vulnerability to Contamination. Water Resources Management, 30, 1549-1566. https://doi.org/10.1007/s11269-016-1239-4

[15] Doerfliger, N., Jeannin, P. and Zwahlen, F. (1999) Water Vulnerability Assessment in Karst Environments: A New Method of Defining Protection Areas Using a MultiAttribute Approach and GIS Tools (EPIK Method). Environmental Geology, 39, 165-176. https://doi.org/10.1007/s002540050446

[16] Vias, J., Andreo, B., Perles, M. and Carrasco, F. (2005) A Comparative Study of Four Schemes for Groundwater Vulnerability Mapping in a Diffuse Flow Carbonate Aquifer under Mediterranean Climatic Conditions. Environmental Geology, 47, 586-595. https://doi.org/10.1007/s00254-004-1185-y

[17] Hamdan, I., Margane, A., Ptak, T., Wiegand, B. and Sauter, M. (2016) Groundwater Vulnerability Assessment for the Karst Aquifer of Tanour and Rasoun Springs Catchment Area (NW-Jordan) Using COP and EPIK Intrinsic Methods. Environmental Earth Sciences, 75. https://doi.org/10.1007/s12665-016-6281-2

[18] Corniello, A., Ducci, D. and Monti, G.M. (2004) Aquifer Pollution Vulnerability in the Sorrento Peninsula, Southern Italy Evaluated by SINTACS Method. Geofisica Internacional-Mexico, 43, 575-581.

[19] Kumari, S., Jha, R., Singh, V., Baier, K. and Sinha, M.K. (2016) Groundwater Vulnerability Assessment Using SINTACS Model and GIS in Raipur and Naya Raipur, Chhattisgarh, India. Indian Journal of Science and Technology, 9, 1-6.

[20] Al-Shatnawi, A.M., El-Bashir, M.S., Khalaf, R.M.B. and Gazzaz, N.M. (2016) Vulnerability Mapping of Groundwater Aquifer Using SINTACS in Wadi Al-Waleh Catchment, Jordan. Arabian Journal of Geosciences, 9, 67.

https://doi.org/10.1007/s12517-015-2080-4

[21] Goldscheider, N., Klute, M., Sturm, S. and Hötzl, H. (2000) The PI Method-A GISBased Approach to Mapping Groundwater Vulnerability with Special Consideration of Karst Aquifers. Zeitschrift für Angewandte Geologie, 46, 157-166.

[22] Daly, D., Dassargues, A., Drew, D., Dunne, S., Goldscheider, N., Neale, S., Popescu, I. and Zwahlen, F. (2002) Main Concepts of the "European Approach" to KarstGroundwater-Vulnerability Assessment and Mapping. Hydrogeology Journal, 10, 
340-345. https://doi.org/10.1007/s10040-001-0185-1

[23] Goldscheider, N. and Popescu, I. (2004) The European Approach. Vulnerability and Risk Mapping for the Protection of Carbonate (Karst) Aquifers. Final Report COST Action, 620, 17-21.

[24] Saaty, T.L. (1980) The Analytic Hierarchy Process: Planning, Priority Setting, Resources Allocation. Mcgraw-Hill, New York.

[25] Saaty, T.L. (1990) How to Make a Decision: The Analytic Hierarchy Process. European Journal of Operational Research, 48, 9-26. https://doi.org/10.1016/0377-2217(90)90057-I

[26] Malczewski, J. (1996) A GIS-Based Approach to Multiple Criteria Group Decision Making. International Journal of Geographical Information Systems, 10, 955-971. https://doi.org/10.1080/02693799608902119

[27] Saaty, T. and Vargas, L.L.G. (2001) Models, Methods, Concepts, and Applications of the Analytic Hierarchy Process. Kluwer Academic Publishers, Dordrecht.

[28] Saaty, T.L. (1977) A Scaling Method for Priorities in Hierarchical Structures. Journal of Mathematical Psychology, 15, 234-281. https://doi.org/10.1016/0022-2496(77)90033-5

[29] Lodwick, W.A., Monson, W. and Svoboda, L. (1990) Attribute Error and Sensitivity Analysis of Map Operations in Geographical Information Systems: Suitability Analysis. International Journal of Geographical Information Systems, 4, 413-428. https://doi.org/10.1080/02693799008941556

Submit or recommend next manuscript to SCIRP and we will provide best service for you:

Accepting pre-submission inquiries through Email, Facebook, LinkedIn, Twitter, etc. A wide selection of journals (inclusive of 9 subjects, more than 200 journals)

Providing 24-hour high-quality service

User-friendly online submission system

Fair and swift peer-review system

Efficient typesetting and proofreading procedure

Display of the result of downloads and visits, as well as the number of cited articles

Maximum dissemination of your research work

Submit your manuscript at: http://papersubmission.scirp.org/

Or contact jwarp@scirp.org 